\title{
Analysis on the Improved Degree of Grey Incidence of the Coal Industry Production and the Coal Transportation in Shanxi Province
}

\author{
Mao-lin Wang \\ School of International Business \& TJIIDS \\ Tianjin Foreign Studies University \\ Tianjin, China \\ e-mail: wangmaolin@188.com \\ Zheng-jun Ren \\ School Industry Management Office \\ Hebei University of Technology \\ Tianjin, China \\ e-mail: romonank@126.com
}

\author{
Xiao-su Yin \\ School of International Business \\ Tianjin Foreign Studies University \\ Tianjin, China \\ e-mail: yinxiaosu2011@ sina.com \\ Shan Lu \\ School of International Business \\ Tianjin Foreign Studies University \\ Tianjin, China \\ e-mail: nklushan@163.com
}

\begin{abstract}
The basic situation of the coal industry production in Shanxi province was studied in this paper, and the transportation of coal in Shanxi province which was divided into the highway freight and the railway freight was studied. Then, the analysis method of synthetic degree of grey incidence was improved by the three-point estimate method in the program evaluation and review technique method in order to analyze the coordination of coal production and coal transportation more precise. The result showed that the length of railways and the length of highways are the key factors to promote the coal industry production in Shanxi province. And the mean of the improved synthetic degree of grey incidence of the railway transportation of coal and coal industry production in Shanxi province is larger than that of the highway transportation. More attention should be paid to the construction of the railways in order to promote the coal industry production in Shanxi province.
\end{abstract}

Keywords-coal industry production; coal transportation; coordination; synthetic degree of grey incidence; three-point estimate method

\section{INTRODUCTION}

Shanxi province is the largest coal producer in China. The capacity of coal transport has a direct impact on the coal sales and coal production. Therefore, the coordination of coal production and coal transportation was studied in this paper in order to promote the coal sales and coal production in Shanxi province.

The common analysis methodes of coordination include data envelopement analysis, principal component analysis, degree of grey incidence analysis, etc. Among those methodes, the degree of grey incidence analysis is an effective and efficient analysis method of coordination.
Specifically, the degree of grey incidence analysis can be divided into Deng's degree of grey incidence, absolute degree of grey incidence, relative degree of grey incidence, synthetic degree of grey incidence, etc[1,2]. In order to make the synthetic degree of grey incidence more precise, we attempt to improve the analysis method. Specifically, the three-point estimate method in PERT[3,4] method was used to determine the value of the weight coefficient $\theta$ in this paper.

\section{BASIC SITUATION OF THE COAL INDUSTRY PRODUCTION IN SHANXI PROVINCE}

As the data [5-11] shown in Fig .1, in 2012, the coal industry production in Shanxi province reached 91333 ten thousand tons, increased $4.71 \%$ over the previous year and the growth rate decreased 13.02 percentage points. The average annual growth rate of the coal industry production reached $18.19 \%$ between 2007 and 2012 and the coal industry production showed a situation of sustained development in Shanxi province.

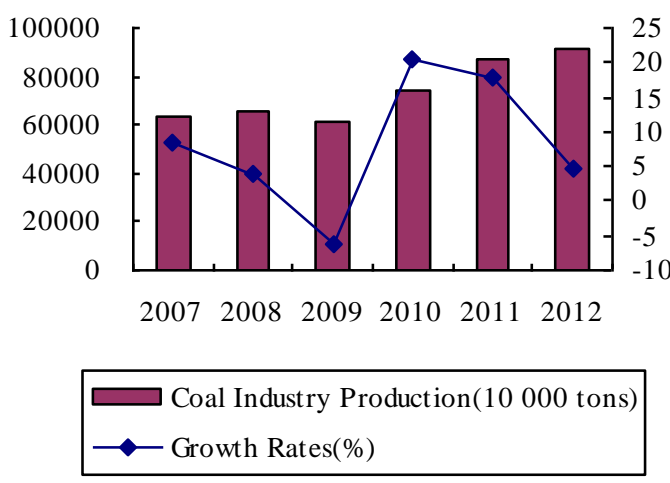

Figure 1. Coal industry production. 


\section{BASIC SITUATION OF THE COAL TRANSPORTATION IN} SHANXI PROVINCE

\section{A. Highway Transportation of the Coal and Products in Shanxi Province}

Highway freight traffic of the coal and products:As the data [5-11] shown in Fig .2, in 2012, the freight traffic of the coal and products in Shanxi province reached 38334 ten thousand tons, increased $9.48 \%$ over the previous year and the growth rate increased 4.63 percentage points. The average annual growth rate of the coal industry production reached $0.79 \%$ between 2007 and 2012 and the freight traffic of the coal and products sketched out a steady pattern in Shanxi province.

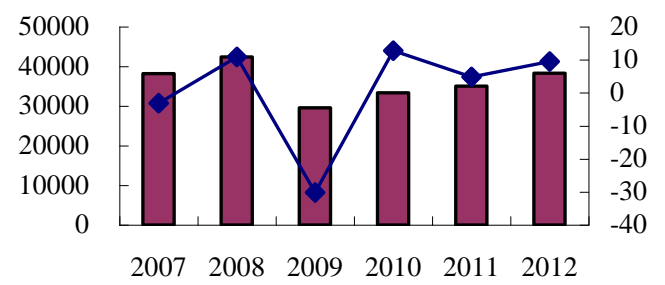

$\square$ Freight Traffic(10 000 tons) $\smile$ Growth Rates(\%)

Figure 2. Highway freight traffic of the coal and products.

Highway turnover volume of freight traffic of the coal and products:As the data [5-11] shown in Fig .3, in 2012, the turnover volume of freight traffic of the coal and products in Shanxi province reached 6199647 ten thousand ton- $\mathrm{km}$, increased $16.15 \%$ over the previous year and the growth rate increased 8.63 percentage points. The average annual growth rate of the turnover volume of freight traffic of the coal and products reached $27.03 \%$ between 2007 and 2012 and the turnover volume of freight traffic of the coal and products showed a rapid development pattern in Shanxi province.
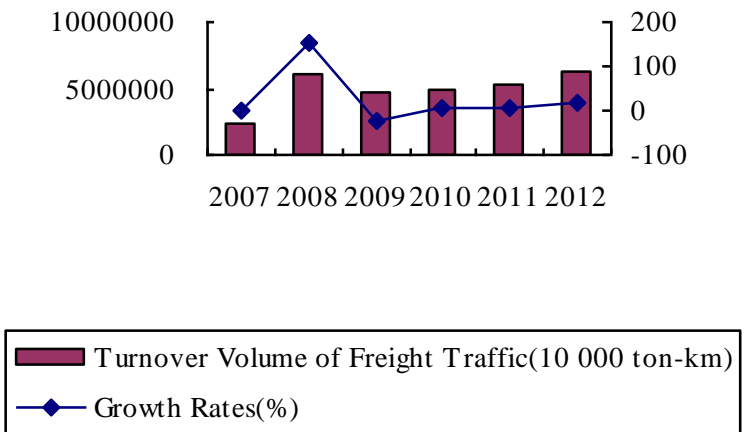

Figure 3. Highway turnover volume of freight traffic of the coal and products.

Length of highways:As the data [11] shown in Fig .4, in 2012, the length of highways in Shanxi province reached $137771 \mathrm{~km}$, increased $2.20 \%$ over the previous year and the growth rate decreased 0.21 percentage points. The average annual growth rate of the coal industry production reached $3.38 \%$ between 2007 and 2012 and the length of highways showed a steady pattern in Shanxi province.

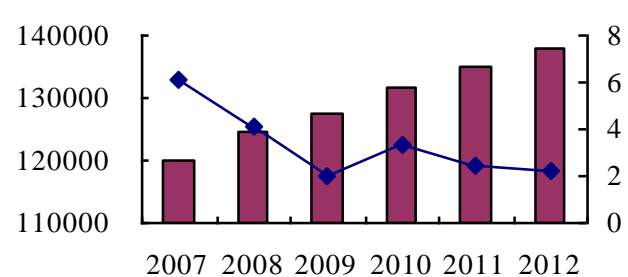

Length of Highways $(\mathrm{km}) \multimap$ Growth Rates(\%)

Figure 4. Length of highways.

Number of civil trucks:As the data [11] shown in Fig .5, in 2012, the number of civil trucks in Shanxi province reached 567788 unit, decreased $7.33 \%$ over the previous year and the growth rate decreased 17.1 percentage points. The average annual growth rate of the number of civil trucks reached $8.01 \%$ between 2007 and 2012 .

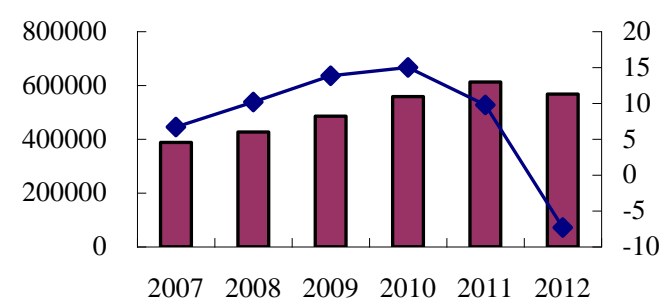

Number of Civil Trucks(unit) - Growth Rates(\%)

Figure 5. Number of civil trucks.

\section{B. Railway Transportation of the Coal and Products in Shanxi Province}

Because of the constraints of data availability, and the coal freight volume is the main body of the railway freight volume, the railway transportation of the coal and products in Shanxi province was replaced by the rail freight traffic in this paper.

Rail freight traffic: As the data [11] shown in Fig .6, in 2012, the rail freight traffic in Shanxi province reached 71437 ten thousand tons, increased $3.24 \%$ over the previous year and the growth rate decreased 5.15 percentage points. The average annual growth rate of the rail freight traffic reached 5.25\% between 2007 and 2012 and the length of highways sketched out a steady development in Shanxi province. 


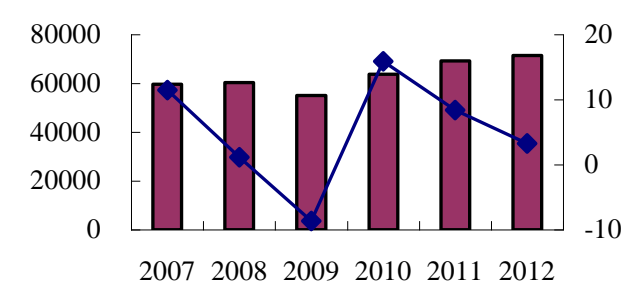

Freight Traffic(10 000 tons) $\smile$ Growth Rates(\%)

Figure 6. Rail freight traffic in Shanxi province.

Rail turnover volume of freight traffic in Shanxi province:As the data [11] shown in Fig .7, in 2012, the rail turnover volume of freight traffic in Shanxi province reached 21435390 ten thousand ton-km, increased $5.30 \%$ over the previous year and the growth rate decreased 44.1 percentage points. The average annual growth rate of the rail turnover volume of freight traffic reached $12.47 \%$ between 2007 and 2012 in Shanxi province.

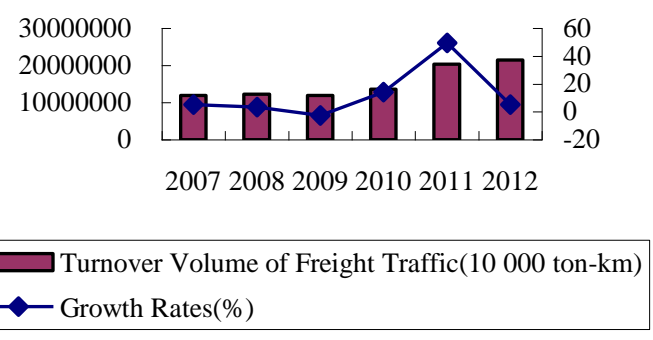

Figure 7. Rail turnover volume of freight traffic in Shanxi province.

Length of railways in operation:As the data [11] shown in Fig .8, in 2012, the length of railways in Shanxi province reached $3774 \mathrm{~km}$, the same as the previous year, and the growth rate decreased 0.59 percentage points. The average annual growth rate of the coal industry production reached $3.32 \%$ between 2007 and 2012 and the length of railways showed a steady pattern in Shanxi province.
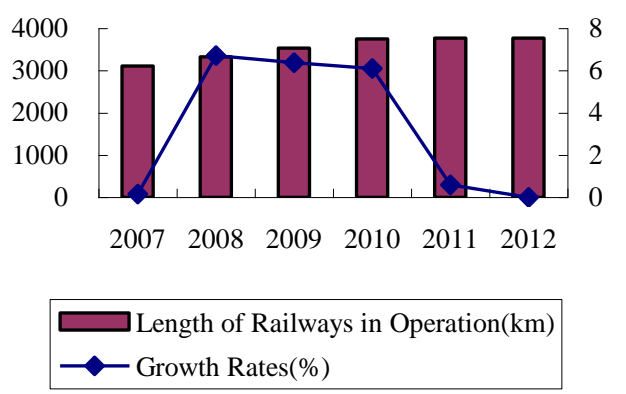

Figure 8. Length of railways in operation.

Locomotives of Taiyuan railway bureau:As the data [511] shown in Fig .9, in 2012, the locomotives of Taiyuan railway bureau reached 1111 unit, decreased $4.39 \%$ over the previous year and the growth rate decreased 6.23 percentage points. The average annual rate of decline of the locomotives of Taiyuan railway bureau reached $0.41 \%$ between 2007 and 2012. Though the number of the locomotives decreased, the performance of the locomotives had been improved. And the rail freight traffic and the rail turnover volume of freight traffic showed a steady growth trend between 2007 and 2012 in Shanxi province.

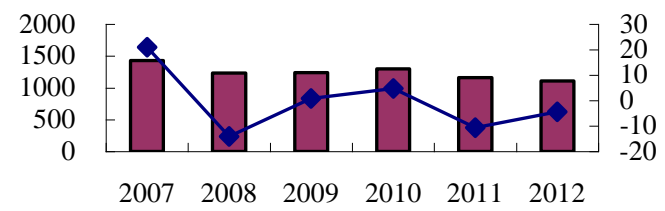

$2007 \quad 2008 \quad 2009 \quad 2010 \quad 2011 \quad 2012$

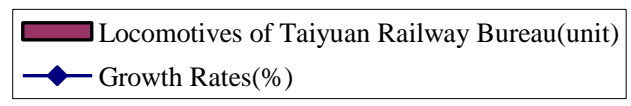

Figure 9. Locomotives of Taiyuan railway bureau.

IV. CALCULATION OF THE IMPROVED SYNTHETIC DEGREE OF GREY INCIDENCE OF THE COAL INDUSTRY PRODUCTION AND THE COAL TRANSPORTATION IN SHANXI PROVINCE

In this paper, the synthetic degree of grey incidence is represented by $\rho_{\mathrm{ij}}$, the absolute degree of grey incidence is represented by $\varepsilon_{\mathrm{ij}}$, and the relative degree of grey incidence is represented by $r_{i j}$. For sequence data $X_{i}$, the equations of calculating the degrees of grey incidence are as follows[12]:

$$
\rho_{i j}=\theta_{e} \varepsilon_{i j}+\left(1-\theta_{e}\right) r_{i j}
$$

$$
\begin{gathered}
\varepsilon_{i j}=\frac{1+\left|s_{i}\right|+\left|s_{j}\right|}{\left|s_{i}\right|+\left|s_{j}\right|+\left|s_{i}-s_{j}\right|} \\
r_{i j}=\frac{1+\left|s_{i}^{\prime}\right|+\left|s_{j}^{\prime}\right|}{\left|s_{i}^{\prime}\right|+\left|s_{j}^{\prime}\right|+\left|s_{i}^{\prime}-s_{j}^{\prime}\right|}
\end{gathered}
$$

As in (1),

$$
\theta_{e}=(a+4 m+b) / 6
$$

As in (4), a, b and $\mathrm{m}$ are respectively the minimum value, maximum value and the most likely value of the weight coefficient $\theta$.

As in (2) and (3),

$$
s_{i}=\int_{1}^{n}\left(X_{i}-x_{i}(1)\right) d t
$$


In this paper, the values of $\mathrm{a}, \mathrm{b}$ and $\mathrm{m}$ were respectively $0.12,0.52$ and 0.44 by the scoring of some experts. Then these results were substituted into (4), and the value of $\theta_{\mathrm{e}}$ was 0.4 .

We use $\mathrm{Y}$ to represent the coal industry production. And we use $\mathrm{H} 1, \mathrm{H} 2, \mathrm{H} 3$ and $\mathrm{H} 4$ respectively to represent the freight traffic(10 000 tons), turnover volume of freight traffic $(10000$ ton-km), length of highways $(\mathrm{km})$ and number of civil trucks(unit) in the highway transportation. Besides, we use $\mathrm{R} 1, \mathrm{R} 2, \mathrm{R} 3$ and $\mathrm{R} 4$ respectively to represent the freight traffic(10 000 tons), turnover volume of freight traffic $(10000$ ton-km), length of railways $(\mathrm{km})$ and locomotives of Taiyuan railway bureau (unit) in the railway transportation.

According to the primary data [5-11] in Fig .1 to Fig .9, and the above calculation formulas, (1), (2), (3) and (5), we can get the calculation results, which are shown in TABLE I and TABLE II :

TABLE I. MATRIX OF THE CALCULATION OF SYNTHETIC DEGREE OF GREY INCIDENCE OF COAL INDUSTRY PRODUCTION AND THE HIGHWAY TRANSPORTATION

\begin{tabular}{|c|c|c|c|c|c|}
\hline $\mathbf{Y}$ & $\varepsilon_{\mathrm{ij}}$ & $\mathbf{r}_{\mathrm{ij}}$ & $\rho_{\mathrm{ij}}$ & $\begin{array}{c}\text { Ranking } \\
\text { of } \rho_{i j}\end{array}$ & $\begin{array}{r}\text { Mean } \\
\text { of } \rho_{i j}\end{array}$ \\
\hline $\mathrm{H} 1$ & 0.6227 & 0.8167 & 0.7391 & 2 & \multirow{4}{*}{0.7255} \\
\hline $\mathrm{H} 2$ & 0.5019 & 0.6055 & 0.5641 & 4 & \\
\hline $\mathrm{H} 3$ & 0.9755 & 0.8460 & 0.8978 & 1 & \\
\hline $\mathrm{H} 4$ & 0.5405 & 0.8081 & 0.7011 & 3 & \\
\hline
\end{tabular}

TABLE II. MATRIX OF THE CALCULATION OF SYNTHETIC DEGREE OF GREY INCIDENCE OF COAL INDUSTRY PRODUCTION AND THE RAILWAY TRANSPORTATION

\begin{tabular}{|c|c|c|c|c|c|}
\hline $\mathbf{Y}$ & $\varepsilon_{\mathrm{ij}}$ & $\mathbf{r}_{\mathrm{ij}}$ & $\rho_{\mathrm{ij}}$ & $\begin{array}{c}\text { Ranking } \\
\text { of } \rho_{\mathrm{ij}}\end{array}$ & $\begin{array}{r}\text { Mean } \\
\text { of } \rho_{\mathrm{ij}}\end{array}$ \\
\hline $\mathrm{R} 1$ & 0.6572 & 0.7944 & 0.7395 & 3 & \multirow{4}{*}{0.7547} \\
\hline $\mathrm{R} 2$ & 0.5016 & 0.8592 & 0.7161 & 4 & \\
\hline R3 & 0.5223 & 0.9703 & 0.7911 & 1 & \\
\hline $\mathrm{R} 4$ & 0.5094 & 0.9474 & 0.7722 & 2 & \\
\hline
\end{tabular}

\section{CONCLUSIONS}

As shown in TABLE I, the order of the improved synthetic degree of grey incidence of the four evaluation indexes of the highway transportation of coal and coal industry production in Shanxi province is as: H3> H1> $\mathrm{H} 4>\mathrm{H} 2$, so the coordination of the length of highways and coal industry production is the best, which is followed by freight traffic 、 number of civil trucks and turnover volume of freight traffic. Therefore, we should further increase the investment of the length of highways.

In addition, we can also see that the order of the improved synthetic degree of grey incidence of the four evaluation indexes of the railway transportation of coal and coal industry production in Shanxi province is as: R3> R4> R1> R2, so the coordination of the length of railways and coal industry production is the best, which is followed by locomotives of Taiyuan railway bureau v freight traffic and turnover volume of freight traffic. Therefore, we should also further increase the investment of the length of railways.

Moreover, as shown in TABLE I and TABLE II, the mean of the improved synthetic degree of grey incidence of the the railway transportation of coal and coal industry production in Shanxi province is larger than that of highway. The capacity of railway transport is larger than the capacity of highway transport. So we should further strengthen the construction of railway transport in Shanxi province, especially the length of railways, the purpose is to promote the coal industry production in Shanxi province.

\section{REFERENCES}

[1] Y. Fan, L.L. Li and X.G. Tong, etc., "Fiscal and Financial Policies on the Chinese High - tech Industry Cluster Effect Analysis-Based on Five Major Industries Grey Overall Connection Degree," Science and Technology Management R esearch, Jul. 2014, pp. 177-180, doi:10.3969/j.issn.1000-7695.2014.07.037.

[2] F.F. Dong, X.Y. Luo and B.H. Lu, "Analysis of Impact Factors of Natural Gas Pipeline Internal Corrosion based on the Grey Comprehensive Correlation," Journal of Safety and Environment, vol . 14, Oct. 2014, pp. 15-18, doi:10.13637/j.issn.10096094.2014.05.005.

[3] S. Yin, Y.M. Shan and W. Zhou, etc., "Application of PE R T Network in Oil-Gas Field Development," Journal of Guilin University of Technology, vol. 33, Nov. 2013, pp. 640-645, doi:10.3969/j.issn.1674-9057.2013.04.011

[4] H.X. Meng, G.M. Chen and Y. Zhu, etc., "PER T-based Design of LM R P Cap Emergency Operation for Deepwater Blowout," Vol.10, Feb.2014 pp. 114-119, doi:10.11731/j.issn.1673-193x. 2014.02.019.

[5] Statistics Bureau of Shanxi, Shanxi Survey Office of the National Statistics Bureau, Shanxi Statistical Year Book, China Statistics Press: Beijing, 2007[Online edition, No pp., www.stats-sx.gov.cn].

[6] Statistics Bureau of Shanxi, Shanxi Survey Office of the National Statistics Bureau, Shanxi Statistical Year Book, China Statistics Press: Beijing, 2008[Online edition, No pp., www.stats-sx.gov.cn].

[7] Statistics Bureau of Shanxi, Shanxi Survey Office of the National Statistics Bureau, Shanxi Statistical Year Book, China Statistics Press: Beijing, 2009[Online edition, No pp., www.stats-sx.gov.cn].

[8] Statistics Bureau of Shanxi, Shanxi Survey Office of the National Statistics Bureau, Shanxi Statistical Year Book, China Statistics Press: Beijing, 2010[Online edition, No pp., www.stats-sx.gov.cn].

[9] Statistics Bureau of Shanxi, Shanxi Survey Office of the National Statistics Bureau, Shanxi Statistical Year Book, China Statistics Press: Beijing, 2011[Online edition, No pp., www.stats-sx.gov.cn].

[10] Statistics Bureau of Shanxi, Shanxi Survey Office of the National Statistics Bureau, Shanxi Statistical Year Book, China Statistics Press: Beijing, 2012[Online edition, No pp., www.stats-sx.gov.cn].

[11] Statistics Bureau of Shanxi, Shanxi Survey Office of the National Statistics Bureau, Shanxi Statistical Year Book, China Statistics Press: Beijing, 2013[Online edition, No pp., www.stats-sx.gov.cn].

[12] S.F. Liu , Y.G. Dang, Z.G. Fang, etc. Grey System Theory and Its Application, 5th ed., Science Press: Beijing, 2010, pp.62-84. 